\title{
Coupled velocity and temperature measurements in an air-filled differentially heated cavity at $\mathrm{Ra}=1.2 \mathrm{E} 11$
}

\author{
P. Belleoud*, D. Saury ${ }^{1}$, D. Lemonnier \\ Institut Pprime - UPR 3346, CNRS - ENSMA - Université de Poitiers \\ Département Fluides, Thermique et Combustion, ENSMA, Téléport 2 \\ 1 avenue Clément Ader - BP 40109, \\ F-86961 Futuroscope Chasseneuil CEDEX, France.
}

\begin{abstract}
The experimental work described in this paper presents a turbulent natural convection flow at high Rayleigh number $\left(\mathrm{Ra}_{\mathrm{H}}=1.2 \times 10^{11}\right)$ within a $4 \mathrm{~m}$-high differentially heated cavity filled with air. Synchronized measurements of velocity and temperature have been developed to describe the turbulent behavior of the flow. For this purpose, this coupled acquisition leads, among others, to the calculation of turbulent heat fluxes. These fluxes are provided in this paper and compared to other turbulent quantities (Reynolds stresses for instance). The synchronization of the acquisitions of velocity and temperature has been set up by the coupling of PIV and micro-thermocouple $(\varnothing=12.7 \mu \mathrm{m})$ measurements. Buoyant effects as well as velocity-temperature interactions on such a turbulent flow are discussed in this paper.
\end{abstract}

\section{Nomenclature}

D Depth of the cavity: $\mathrm{D}=0.86 \mathrm{~m}[\mathrm{~m}]$

F $\quad$ Flatness coefficient: $F=\left\langle\left[\frac{X-\langle X\rangle}{\sigma_{X}}\right]^{4}\right\rangle[-]$

g Gravitational acceleration $\left[\mathrm{m} \cdot \mathrm{s}^{-2}\right]$

$\mathrm{H} \quad$ Height of the cavity: $\mathrm{H}=3.84 \mathrm{~m}[\mathrm{~m}]$

$\mathrm{k}$ Thermal conductivity $\left[\mathrm{W} \cdot \mathrm{m}^{-1} \cdot \mathrm{K}^{-1}\right]$

$k^{*} \quad$ 2D dimensionless turbulent kinetic energy: $k^{*}=\frac{\left\langle{V^{*}}^{2}\right\rangle+\left\langle{W^{*}}^{2}\right\rangle}{2}[-]$

L Width of the cavity: $\mathrm{L}=1 \mathrm{~m}[\mathrm{~m}]$

$\mathrm{N} \quad$ Number of samples

p Pressure $[\mathrm{Pa}]$

${ }^{1}$ Corresponding author: didier.saury@ensma.fr 
$\mathrm{p}_{\mathrm{m}} \quad$ Motion pressure $[\mathrm{Pa}]$

RaH $\quad$ Rayleigh number: $R a_{H}=\frac{g \beta \Delta T_{r e f} H^{3}}{v \alpha}[-]$

$\mathrm{r} \quad$ Cross correlation coefficient [-]

S Skewness coefficient: $S=\left\langle\left[\frac{X-\langle X\rangle}{\sigma_{X}}\right]^{3}\right\rangle[-]$

$\mathrm{T} \quad$ Air temperature $\left[{ }^{\circ} \mathrm{C}\right]$

$\mathrm{T}_{0} \quad$ Ambient temperature $\left(\approx 20^{\circ} \mathrm{C}\right)$ or averaged temperature $T_{0}=\frac{T_{h}+T_{C}}{2}\left[{ }^{\circ} \mathrm{C}\right]$

$\mathrm{t} \quad$ Time $[\mathrm{s}]$

$\mathrm{t}^{*} \quad$ Dimensionless time: $t^{*}=\alpha t \sqrt{R a_{H}} / H^{2}$

$\mathrm{V}_{\text {ref }} \quad$ Reference velocity: $V_{\text {ref }}=\alpha / H \times \sqrt{R a_{H}}\left[\mathrm{~m} . \mathrm{s}^{-1}\right]$

$\mathrm{V} \quad$ Horizontal component of the velocity (in the y-direction) $\left[\mathrm{m} \cdot \mathrm{s}^{-1}\right]$

$\mathrm{V}^{*} \quad$ Dimensionless horizontal component of the velocity (in the y-direction): $V^{*}=V / V_{\text {ref }}[-]$

W Vertical component of the velocity (in the z-direction) $\left[\mathrm{m} . \mathrm{s}^{-1}\right]$

$\mathrm{W}^{*} \quad$ Dimensionless vertical component of the velocity (in the z-direction): $W^{*}=W / V_{\text {ref }}[-]$

Y Horizontal Cartesian coordinate $[\mathrm{m}]$

$\mathrm{Y}^{*} \quad$ Dimensionless horizontal Cartesian coordinate: $Y=y / H[-]$

Z Vertical Cartesian coordinate $[\mathrm{m}]$

Z* Dimensionless vertical Cartesian coordinate: $Z=z / H[-]$

\section{Greek characters}

$\alpha \quad$ Thermal diffusivity $\left[\mathrm{m}^{2} \cdot \mathrm{s}^{-1}\right]$

$\beta \quad$ Coefficient of thermal expansion: $\beta=1 / T_{0}\left[\mathrm{~K}^{-1}\right]$

$\delta \quad$ Dimensionless dynamic boundary layer thickness [-]

$\delta_{\text {th }} \quad$ Dimensionless thermal boundary layer thickness [-]

$\Delta \mathrm{T}_{\text {ref }} \quad$ Temperature difference: $\Delta T_{\text {ref }}=T_{h}-T_{c}[\mathrm{~K}]$

$\varepsilon \quad$ Measured hemispheric global emissivity [-]

$\rho_{0} \quad$ Air density at $\mathrm{T}_{0}\left[\mathrm{~kg} \cdot \mathrm{m}^{-3}\right]$

$\sigma_{\mathrm{X}} \quad$ Standard deviation of the quantity X: $\sigma_{X}=\sqrt{\left\langle[X-\langle X\rangle]^{2}\right\rangle}$ 
$\theta \quad$ Dimensionless temperature: $\theta=\left(T-T_{0}\right) / \Delta T_{\text {ref }}[-]$

$v \quad$ Kinematic viscosity of the air $\left[\mathrm{m}^{2} \mathrm{~s}^{-1}\right]$

\section{Subscripts and superscripts}

c Cold wall

core Core of the cavity

h Hot wall

$\langle\cdot\rangle \quad$ Mean value: $\langle X\rangle=1 / N \times \sum_{i=1}^{N} X_{i}$

RMS fluctuations: $X^{\prime}=\sigma_{X}$

\section{Introduction}

In many cases, natural convection appears when a temperature gradient is associated to gravity forces and the understanding of this phenomenon is necessary to quantify the heat transfers that it induces. Thermal natural convection flows in confined spaces are usually turbulent (large dimensions and/or temperature difference). Therefore, improving the knowledge of this kind of regime and associated heat and mass transfers is crucial. Experimentally speaking, the differentially heated cavity (DHC) is a very propitious experimental device to study natural convection. For decades, this phenomenon has widely been investigated from theoretical, experimental and numerical point of view for laminar regimes [1, 2]. The studies for high Raleigh numbers remain mostly numerical [3-9]. However, some studies dealing with the transition to a turbulent regime in the hot boundary layer can be found [10]. With its outstanding dimensions $\left(4 \mathrm{~m}^{3}\right)$ the DHC generates natural convection flows at high Rayleigh Numbers under Boussinesq approximation (up to $1.2 \times 10^{11}$ ). To deepen first results on this DHC [11] concerning dynamic and thermal behaviors, coupled and synchronized velocity and temperature measurements were carried out to evaluate turbulent quantities such as turbulent heat fluxes, turbulent kinetic energy or temperature variance. In addition, to improve the understanding of turbulent behavior of such flows, the access to experimental values of turbulent heat fluxes is a real asset to 
upgrade numerical simulations like the RANS approaches. Indeed, in such models, turbulent heat fluxes are unknown and have to be numerically modeled.

Some methods of measurement had already been used to evaluate these turbulent fluxes; however, most of them cannot be applied in this case. As an example, methods coupling cold and hot wires will be too intrusive as it disrupts the natural convection flow. Indeed, the temperature of the hot wire will induce an additional parasitic flow in the vicinity of the probe. In order to avoid this phenomenon, Thole and Bogard [12] proposed a method involving a cold wire $(0.64 \mu \mathrm{m})$ for the measurements of temperature and the two components Laser Doppler Velocity (LDV 2D) also used later by Pietri et al [13]. Some studies were carried out using LDV coupled to thermistors [14] or a thin K-type thermocouple $(\varnothing 25 \mu \mathrm{m})$ [15]. Nevertheless, as the velocity measurement is triggered when the particle passes through the measuring volume made by the intersection of the laser beams, LDV measurements are hardly usable because acquisition frequency cannot be controlled. Thus, the synchronization of velocity measurements with the temperature frequency acquisitions is compromised. The interest of PIV is precisely to set measurement frequency in order to synchronize the triggering of both velocity and temperature acquisitions. More recently some works were conducted to synchronize PIV measurements and PLIF $[16,17]$ that presents the advantage to provide synchronized fields of velocity and temperature. However, in the case of the DHC, the limited accessibility of the inside of the cavity and the low range of resolution of PLIF for temperature measurement in gas, make this technique is not suitable to the small temperature variations existing in the DHC. The measurements technique presented in the following paper consists in coupling PIV measurements to micro-thermocouple. This method has been successfully tested firstly on a small dimension vertical channel [18] before being adapted to the $4 \mathrm{~m}$ high differentially heated cavity. Therefore, a real time process protocol has carefully been established to synchronize the two kinds of measurement technique. The ease of access to this first setup permitted to define experimental precautions like the minimum distance between the laser light sheet and the thermocouple in order to 
have the two measurements as close as possible and avoid interference between them (warming of the thermocouple by the energy of the laser).

The following paper will present the coupled velocity and temperature measurement within a turbulent natural convection flow in a differentially heated cavity with a vertical aspect ratio of 4 . The experimental setup will be first described and some results on statistical moments of the temperature and the velocity will be provided. Then, turbulent heat fluxes strictly speaking will be presented and compared to other turbulent quantities (turbulent kinetic energy, temperature variance). Finally, a discussion on the turbulent transfer will arise.

\section{Experimental device}

\subsection{Description of the 4m-high DHC}

The measurements presented below were conducted in a differentially heated cavity filled with air. The inner dimensions of the cavity are $3.84 \mathrm{~m}$ in high (H), $1 \mathrm{~m}$ in width (L) and $0.86 \mathrm{~m}$ in depth (D). The motion of the air is due to the temperature gradient induced between two opposite isothermal vertical walls. One of these walls is cooled while the other one is heated to maintain a temperature difference of $20^{\circ} \mathrm{C}$ equally distributed around the ambient temperature corresponding to a Rayleigh number equal to $1.2 \times 10^{11}$. Both the vertical isothermal walls are made of aluminum plate (AU4G, $\mathrm{k}=134 \mathrm{~W} \mathrm{~m}^{-1} \mathrm{~K}^{-1}$ and $\varepsilon=0.15$ ) and their temperature is prescribed thanks to a glycol-water flow regulated by two cryothermostats. Temperature difference between the inlet and outlet sections of the two heat exchangers is measured by $6 \mathrm{~K}$-type thermocouples along the rear of these walls and remains lower than $0.1 \mathrm{~K}$. The other walls are made of $8 \mathrm{~cm}$-thick polyurethane foam panels $(k=$ $0.035 \mathrm{~W} \mathrm{~m}^{-1} \mathrm{~K}^{-1}$ ) and the outer part of the cavity is totally covered by additional $3 \mathrm{~cm}$-thick insulation panels $\left(k=0.035 \mathrm{~W} \mathrm{~m}^{-1} \mathrm{~K}^{-1}\right)$. In addition, to reduce the effect of the radiation in the cavity, the inner side of the walls is covered by a $40 \mu \mathrm{m}$-thick low-emissivity film $(\varepsilon=0.1)$. Figure 1 shows a schematic view of the inside of the cavity and the upper and the front parts of the experimental device equipped with the measurements devices. 


\subsection{Metrology}

\subsubsection{Temperature measurements}

The acquisitions of temperature within the cavity had been performed thanks to a K-type microthermocouple $(12.7 \mu \mathrm{m}$ in diameter). This thermocouple is mounted on two pins of $100 \mu \mathrm{m}$ in diameter made of the same material (i.e. chromel or alumel) at the end of a 3-meter-stick. The stick is bent twice in order to be shifted from the measurement plane and has been inserted through a slot in the roof that allows moves along the $\mathrm{Y}$ and $\mathrm{Z}$-axes thanks to a displacement device controlled using a Labview ${ }^{\circledR}$ program and with an uncertainty lower than $50 \mu \mathrm{m}$. Acquisitions are performed with an integration time of 0.1 NPLC (Number of Power Line Circle) that is to say $2 \mathrm{~ms}$. The thermocouple is connected to a nano-voltmeter (NI $4071 \mathrm{DMM}$ ) mounted on a NI-PXI 1031 real time rack and the cold junction is immersed in a water tank where the temperature is measured separately by a 4-wire PT100 probe. The range of the measurement used is $\pm 100 \mathrm{mV}$ with a resolution of $6-1 / 2$ digits up to an acquisition frequency of $100 \mathrm{~Hz}$. It allows to detect temperature variations equal to $1.6 \times 10^{-3} \mathrm{~K}$ with this thermocouple.

\subsubsection{Velocity measurements}

Velocity fields are acquired by PIV measurements using a $100 \mathrm{~Hz}$ double-pulsed laser (Nd-YAG). A second slot has been designed on the roof to pass the laser light sheet. This slot is closed by a glass strip to avoid air leakage. The flow is seeded with 1-5 $\mu \mathrm{m}$ oil particles produced by a Laskin generator at ambient temperature using Shell Ondina Oil. Images are obtained by a Dantec SpeedSense 9040 CCD video camera, facing the front wall of the cavity, perpendicularly to the laser sheet, with a dynamic resolution of 8 bits/pix at a frequency of $25 \mathrm{~Hz}$. Recorded images have a resolution of $1632 \times 1200$ pixels and the lens of the camera is a Macro Nikkor with $105 \mathrm{~mm}$ focal length and 2.8 maximum aperture. The time between frames had been set to $2 \mathrm{~ms}$ to correspond to the temperature integration time. A removable foam panel equipped with a $180 \times 280 \mathrm{~mm}^{2}$ window (Figure 1) allows 
the camera to take pictures at different elevations of the cavity. To determine the local particle-image displacement a cross correlation based algorithm with an interrogation window of $32 \times 32$ pixels had been used. The image analysis is started with an interrogation window of $64 \times 64$ pixels and the vector field obtained at this step is used during the final analysis to appropriately shift the interrogation windows to $32 \times 32$ pixels with $50 \%$ overlapping. The real dimensions of the PIV images in the (Y, Z) plane is $60 \times 80 \mathrm{~mm}^{2}$, leading to a space resolution of $0.81 \times 0.79 \mathrm{~mm}^{2}$ for velocity measurements. The velocity, in the case of the coupled measurements, is averaged over 6000 image pairs at $25 \mathrm{~Hz}$, representing an acquisition duration of $240 \mathrm{~s}$.

\subsubsection{Temperature and velocity measurement synchronization}

The two measurement techniques are synchronized via a pulse generator (BNC 575-8) that regulates the triggering of temperature and velocity acquisitions with a $250 \mathrm{ps}$ pulse resolution. This coupled acquisition system is controlled by a real-time LabVIEW ${ }^{\circledR}$ module. Necessary precautions like the position of the thermocouple probe by respect to the laser light plane had been carefully investigated in $[18]$.

\section{Flow description and validation}

To describe the flow within the DHC Figure 2 shows the topology of this flow in the top $1 / 3^{\text {rd }}$ of the cavity, knowing that the same behavior is expected in the bottom thanks to the centro-symmetry property of the flow [11]. We can then underline 4 different kinds of circulations flows in the vertical mid-depth plane:

1- a first one that follows the walls of the DHC:

- vertical boundary layer flows which develop themselves along the isothermal walls

- horizontal wall-jet flows along the top and the bottom adiabatic walls, 
2- a second one in the upper part of the hot boundary layer which goes down outside of the boundary layer. A part of this airflow flows through the core and feeds the opposite boundary layer at the cold wall,

3- a recirculation at the top of the cavity,

4- another recirculation at the $2 / 3^{\text {rd }}$ of the cavity near the hot wall.

The measurements presented in this paper have been acquired at three locations in the vertical middepth plane at $Z^{*}=0.75, Z^{*}=0.85$ and in the vicinity of the top horizontal wall at mid-width $\left(\mathrm{Y}^{*}=0.13\right)$. These locations are materialized by the lines in Figure 2.

\subsection{Velocity measurement techniques comparison}

The measurements presented here have been performed by synchronizing PIV acquisitions and a thermocouple probe. As it is mentioned in 2.2.3, the method has been checked to avoid any interference between the two acquisition setups. Figure 3 shows a comparison between measurements of the vertical component of the velocity at $Z^{*}=0.85$ acquired with the coupled measurements which are studied here and previous measurements performed by 2D-LDV [11] and PIV [19]. We notice that regardless of the acquisition setup, the vertical component of the velocity follows the same trend. Indeed, the zeros of $\left\langle W^{*}\right\rangle$ are at the same abscissa, $\mathrm{Y}^{*}=0.032$ near the hot wall and $\mathrm{Y}^{*}=0.235$ near the cold one. The same observations for the maximums of velocity can be drawn.

\subsection{Mean and fluctuant quantities}

Profiles presented in Figure 4 to Figure 6 show the evolution of the vertical and the horizontal components of the mean dimensionless velocity, represented with their RMS values (bars), near the isothermal walls at $Z^{*}=0.75$ and $Z^{*}=0.85$. Before further analyses, it has to be noted that the evaluation of the very near wall region is not possible with this measurement method. However, this area has been more precisely investigated in [11]. Near the hot wall, a dynamic boundary layer $\delta$, which defined as the distance from the wall where $\left\langle W^{*}\right\rangle=0$ for the first time (see Figure 9), is driven upward due to buoyancy forces as we can see with the positive values of $\left\langle W^{*}\right\rangle$ until $\mathrm{Y}^{*} \approx 0.033$ for 
both heights (Figure 4, left). Beyond $\mathrm{Y}^{*}=0.033,\left\langle W^{*}\right\rangle$ is negative due to a recirculation zone located at the $2 / 3^{\text {rd }}$ of the cavity near the hot wall [11], see Figure 2 . Near the cold side at these elevations, the flow is only descending along the wall, $\left\langle W^{*}\right\rangle$ is always negative (Figure 4, right). No recirculation area is observed in this cold wall region, but a diminution of the thickness of the dynamic boundary layer can be observed between $Z^{*}=0.85$, where the flow still exhibits unsteady laminar behaviour, and $Z^{*}=0.75$, where the transition to the turbulence starts (as suggested by the evolution of the wall heat flux [20]). The horizontal component of the mean velocity (Figure 5) is slightly positive away from both walls. To the hot side, this can be explained first by the recirculation zone and second by a downward flow that feeds the cold boundary layer at the other side, $\left\langle V^{*}\right\rangle>0$. In addition, notice that $W^{\prime}$ is twice greater than $V^{\prime}$ and that the $V^{\prime}$ are an order of magnitude above its mean values $\left\langle V^{*}\right\rangle$. In Figure 6, the air jet flows along the top wall of the cavity from the hot to the cold side $\left.\left(\left\langle V^{*}\right\rangle\right\rangle 0\right)$, the effect of a recirculation zone at the top of the cavity appears farther from the top wall at $Z^{*} \approx$ 0.95 where $\left\langle V^{*}\right\rangle$ becomes negative.

The Figure 7 presents temperature profiles near the hot and the cold walls. The temperature decreases from the temperature of the hot wall to reach the core temperature that depends on the elevation $Z^{*}$ due to the vertical thermal stratification of the core of the DHC. Then the temperature decreases up to the cold wall temperature. It can be underlined that, at the hot side, the temperature passes through a local minimum of temperature in the outer region of the hot boundary layer. It can be linked to the recirculation zone shown in Figure 2. Indeed, fresh air coming from lower elevation is transported upward by the ascendant boundary layer flow. This cold air is then ejected outside of the boundary layer where the velocity magnitude decreases and where the temperature is higher due to the vertical core stratification. It entails a downward airflow when this air flows towards its "isotherm".

Figure 8 shows the dimensionless temperature profile near the adiabatic top wall of the DHC at mid-width. The adiabatic boundary condition can be pointed out by the very first points (close to the 
horizontal top wall) where the temperature tends to remain constant. That implies therefore that the wall temperature gradient (Nusselt) is equal to zero: there is no heat transfer through the top horizontal wall (adiabatic conditions). The temperature, then, increases due to the horizontal hot wall jet coming from the hot boundary layer. Afterwards, the profile exhibits a linear evolution with the elevation showing the constant thermal stratification of the core of the DHC.

\subsection{Buoyancy effects}

In natural convection temperature and the velocity are strongly coupled. To describe this coupling profiles of the temperature and the vertical component of the related velocity have been superimposed in Figure 9. These measurements have been performed at $Z^{*}=0.85$ near the isothermal vertical hot wall where flow exhibits turbulent behavior.

Three particular zones (named A, B and C in Figure 9) can be defined close to the hot wall:

- Zone A, which corresponds to the near wall. In this region A, the flow is accelerated then reaches a maximum of $\left\langle W^{*}\right\rangle$. It is also sucked towards the hot wall $\left(\left\langle V^{*}\right\rangle<0\right)$. The temperature decreases to the temperature of the core at this elevation, $\theta_{\text {core }}$. Buoyancy effects are dominant in this area.

- Zone $\mathrm{B}$, farther the near wall while $\left\langle W^{*}\right\rangle$ remains positive. In this region, the vertical velocity decreases, some cold air $\left(\langle\theta\rangle<\theta_{\text {core }}\right)$ is transported upward due to dominant viscosity effects. A part of the flow is ejected outside the hot boundary layer $\left(\left\langle V^{*}\right\rangle\right\rangle$ $0)$. Buoyancy effects appear not to be preponderant in this area.

- Zone $\mathrm{C}$, beyond zone B when $\left\langle W^{*}\right\rangle=0$ and up to the core of the cavity, the fresh air, which was conveyed and ejected in zone B, flows downward due to opposite buoyancy forces $\left(\langle\theta\rangle<\theta_{\text {core }}\right)$ becoming again dominant as the airflow velocity magnitude tends towards zero in the core making viscous effects negligible (about $\mathrm{Y}^{*} \approx 0.078$, i.e. $30 \mathrm{~cm}$ $\approx 1 / 3^{\text {rd }}$ of the DHC's width). 
This observation shows the necessity of synchronized measurements for both the temperature and the velocity to better understand the coupling mechanisms of the turbulent flow.

To reinforce this assertion, the cross-correlation coefficient between the velocity components and the temperature are presented Figure 10. These coefficients have been calculated with the following expression:

$$
r(A, B)=\frac{\left\langle A^{\sim} B^{\sim}\right\rangle}{\sigma_{A} \sigma_{B}}
$$

where $A$ and $B$ are two time-dependent signals, $A^{\sim}$ and $B^{\sim}$ their fluctuations and $\sigma_{A}$ and $\sigma_{B}$ their standard deviations.

The same three zones have been delimited and we acknowledge that in the near wall region (zone A) the correlation between the temperature and the components of the velocity is at its maximum, around $50 \%$, where buoyancy forces are particularly active. This correlation decreases then away from the wall with the diminution of the action of buoyancy, in zone B. The negative values of $r\left(W^{*}, \theta\right)$ between $\mathrm{Y}^{*}=0.015$ and 0.045 denote the paradoxical rise of cold air advected due to viscosity effects and whose buoyant effects on the motion are opposed to this motion. On the contrary, the two components of the velocity are less correlated close to the wall. Their correlation coefficient increases away from the wall to reach a plateau between $\mathrm{Y}^{*}=0.01$ and 0.04 (zone B and beyond). This area corresponds to a shear zone between the ascending and the descending flow. Finally, in zone C, cold air goes downward, the flow is again driven by buoyancy forces (inducing an increase of $r\left(W^{*}, \theta\right)$ ).

\section{Turbulent quantities}

The behavior of the flow and the associated heat transfer in the DHC are described by the NavierStokes equations for a Newtonian and isovolume fluid in an unsteady state under the Boussinesq approximation:

$$
\begin{gathered}
\nabla \cdot \vec{V}=0 \\
\frac{\partial \vec{V}}{\partial t}+\vec{V} \cdot \bar{\nabla} \vec{V}=-\frac{1}{\rho_{0}} \vec{\nabla} p_{m}-\beta\left(T-T_{0}\right) \vec{g}+v \overline{\bar{\Delta}} \vec{V}
\end{gathered}
$$




$$
\frac{\partial T}{\partial t}+\vec{V} \cdot \vec{\nabla} T=\alpha \nabla^{2} T
$$

where $p_{m}$ is the motion pressure defined by: $p_{m}=p+\rho_{0} g Z$ with $\rho_{0}$ the air density at $T_{0}=\frac{T_{h}+T_{c}}{2}$.

Focusing on the energy conservation equation, (4) can be rewritten in a dimensionless form:

$$
\frac{\partial \theta}{\partial t^{*}}+\nabla\left(\theta \overrightarrow{V^{*}}-\frac{1}{\sqrt{R a_{H}}} \vec{\nabla} \theta\right)=0
$$

where the reference velocity is related to the Rayleigh number by $V_{r e f}=\frac{\alpha}{H} \sqrt{R a_{H}}$. We consider then the Reynolds average of equation (5) that raises the dimensionless turbulent heat fluxes $\left\langle V^{* \prime} \theta^{\prime}\right\rangle$ and $\left\langle W^{*^{\prime}} \theta^{\prime}\right\rangle$. Measurements are performed in the mid-depth plane of the cavity, which is a symmetry plane where the mean flow is assumed to be bi-dimensional [21, 22] and statistically steady. This equation becomes (6) in Cartesian coordinate:

$$
\frac{\partial}{\partial Y^{*}}\left(\langle\theta\rangle\left\langle V^{*}\right\rangle+\left\langle V^{*^{\prime}} \theta^{\prime}\right\rangle-\frac{1}{\sqrt{R a_{H}}} \frac{\partial\langle\theta\rangle}{\partial Y^{*}}\right)+\frac{\partial}{\partial Z^{*}}\left(\langle\theta\rangle\left\langle W^{*}\right\rangle+\left\langle W^{\prime} \theta^{\prime}\right\rangle-\frac{1}{\sqrt{R a_{H}}} \frac{\partial\langle\theta\rangle}{\partial Z^{*}}\right)=0
$$

The three means of energy transfers are therefore emphasized in equations (6):

- the transport due to the mean flow $\left(\langle\theta\rangle\left\langle V^{*}\right\rangle\right.$ and $\left.\langle\theta\rangle\left\langle W^{*}\right\rangle\right)$

- the transfer due to the fluctuating flow $\left(\left\langle V^{* \prime} \theta^{\prime}\right\rangle\right.$ and $\left.\left\langle W^{* \prime} \theta^{\prime}\right\rangle\right)$

- the conductive heat transfer $\left(\frac{1}{\sqrt{R a_{H}}} \frac{\partial\langle\theta\rangle}{\partial Y^{*}}\right.$ and $\left.\frac{1}{\sqrt{R a_{H}}} \frac{\partial\langle\theta\rangle}{\partial Z^{*}}\right)$

\subsection{Turbulent heat fluxes}

The synchronization of velocity and temperature measurements highlights the coupling that exists between these quantities in natural convection. This can also be useful for the calculation of the (dimensionless) turbulent heat fluxes, $\left\langle V^{* \prime} \theta^{\prime}\right\rangle$ and $\left\langle W^{* \prime} \theta^{\prime}\right\rangle$.

Figure 11 presents the horizontal dimensionless turbulent heat flux $\left\langle V^{*^{\prime}} \theta^{\prime}\right\rangle$ (top) and the vertical one $\left\langle W^{*^{\prime}} \theta^{\prime}\right\rangle$ (bottom) at $Z^{*}=0.75$ and 0.85 . Whatever the elevation, the flux increases up to a maximum when the buoyancy forces are dominant, that is to say in the thermal boundary layers, which is defined as the distance $\delta_{\text {th }}$ from the wall where $\langle\theta\rangle=\theta_{\text {core }}$ for the first time (see Figure 9$),\left(0<\mathrm{Y}^{*}<0.008\right.$ for 
the hot side and $0.25<\mathrm{Y}^{*}<0.26$ for the cold side at these $\left.\mathrm{Z}^{*}\right)$. These maximums are twice higher for the vertical component $\left\langle W^{* \prime} \theta^{\prime}\right\rangle$ than the horizontal one $\left\langle V^{*^{\prime}} \theta^{\prime}\right\rangle$ near the hot wall and four times higher near the cold wall. Then, these turbulent heat fluxes decrease until a minimum that can be negative (hot side here), when the temperature reaches a minimum too.

In addition, depending on the elevation, a different behavior to the cold side can be noticed. Indeed, at $Z^{*}=0.75$, the turbulent heat fluxes exhibit a plateau before decreasing to null values. This plateau is due to the feeding of the cold boundary layer by an airflow ejected from the hot boundary layer (see for instance Figure 2 or [11]). This phenomenon is much more noticeable at $Z^{*}=0.75$ where the airflow coming from the hot side is more significant.

Statistical distribution the dimensionless turbulent heat fluxes have been pointed out at five different horizontal locations near the hot wall for $Z^{*}=0.75$ and 0.85 . These locations have been chosen according to the following specifications and are illustrated in Figure 9:

1) in the very near-wall region (zone A) where the buoyancy forces are the most significant $\left(\mathrm{Y}^{*}=0.003\right.$, zone $\left.\mathrm{A}\right)$

2) outside of the thermal boundary layer $\left(\mathrm{Y}^{*}=0.013\right.$, zone $\mathrm{B}$, close to the zone A)

3) when fresh air is driven upward by viscosity (zone B) as the temperature is a passive scalar $\left(\mathrm{Y}^{*}=0.02\right.$, zone $\left.\mathrm{B}\right)$

4) in the shear zone between the ascending and the descending flow $\left(\mathrm{Y}^{*}=0.03\right.$, zone $\mathrm{B}$ close to the zone C)

5) in the descending flow (zone C).

The turbulent heat flux distributions have been plotted in Figure 12 and Figure 13. For both elevations an inversion of the skewness can be observed especially for the vertical turbulent heat flux $\left\langle W^{*^{\prime}} \theta^{\prime}\right\rangle$. Indeed, near the hot wall in the high buoyancy force zone, values of the fluxes are mostly distributed below the mean (positive skewness) with a large discrepancy. Here, the turbulent fluxes are then 
positive. Away from the wall (zone B), the skewness decreases where the temperature becomes a passive scalar transported by the flow. The skewness is almost null (i.e. values are equally distributed around the mean value) in the shear zone between zone $\mathrm{B}$ and zone $\mathrm{C}$ and becomes negative in zone $\mathrm{C}$ where the fresh air then driven by viscosity tends to come back down to the elevation of its isotherm. Turbulent behavior of the flow close to the isothermal wall is also confirmed close to the hot wall with the large discrepancy of the turbulent heat fluxes, which gradually decreases (i.e. flatness increases) away from the wall as seen on the heat flux distributions.

\subsection{Energy transfer}

As it is mentioned in the beginning of this part, the energy transfer can be divided into three contributions: the conductive heat transfer, the transport by the mean flow and the turbulent heat transfers. Figure 14 presents a comparison between the heat transfer due to fluctuating quantities (turbulent heat fluxes) and the heat diffusion of the mean temperature at $Z^{*}=0.75$ (the same conclusions can be drawn at $Z^{*}=0.85$ ). Close to the hot wall, the heat transfer is obviously mostly driven by the diffusion along the horizontal direction. Far from the wall, the transfer of the heat due to the conduction becomes negligible when comparing the dimensionless turbulent heat fluxes and advection of the mean flow (Figure 17). Turbulent heat fluxes are then compared to the mean heat fluxes in Figure 15. In the thermal boundary layer, (named zone A in Figure $9, Y^{*} \leq 0.008$ ) the horizontal turbulent heat flux $\left\langle V^{*^{\prime}} \theta^{\prime}\right\rangle$ is greater than the mean horizontal heat flux $\left\langle V^{*}\right\rangle\langle\theta\rangle$ but this trend reverses on the outer part of the thermal boundary layer where a part of the ascending airflow is towards the core. Concerning the vertical direction, the mean heat flux $\left\langle W^{*}\right\rangle\langle\theta\rangle$ is almost everywhere one order of magnitude higher than the vertical turbulent heat fluxes $\left\langle W^{* \prime} \theta^{\prime}\right\rangle$. The same conclusions are drawn when examining the heat transfers (not presented here) near the cold wall. This simple comparison underlines the importance of the suitable modeling of the turbulent heat fluxes for turbulent natural convection flows. 
4.3. Reynolds stresses and temperature variance

To complete this study of the turbulent heat fluxes, profiles of the dimensionless Reynolds stresses $\left\langle V^{* \prime} W^{* \prime}\right\rangle$ and of the variance of the dimensionless temperature $\left\langle\theta^{\prime 2}\right\rangle$ are compared to the turbulent heat fluxes $\left(\left\langle V^{*^{\prime}} \theta^{\prime}\right\rangle\right.$ and $\left.\left\langle W^{*^{\prime}} \theta^{\prime}\right\rangle\right)$ in Figure 16. As a first observation, $\left\langle W^{*^{\prime}}{ }^{2}\right\rangle$ is three times higher than $\left\langle V^{*^{\prime}}{ }^{2}\right\rangle$. This difference of magnitude between the two diagonal terms of the strain tensor shows the anisotropic nature of the flow. We also notice that the vertical turbulent heat flux $\left\langle W^{* \prime} \theta^{\prime}\right\rangle$ and the vertical turbulent kinetic energy $\left\langle W^{*^{\prime}}{ }^{2}\right\rangle$ are of the same order of magnitude in the thermal boundary layer, very close to the hot wall. However, the variance of the temperature $\left\langle\theta^{\prime 2}\right\rangle$ is about five or six times higher than the turbulent heat fluxes and the Reynolds stresses (see Figure 16) in this near-wall region. This last quantity is used to compare thermal to motion time scales [23-25]. Figure 16 (bottom) shows a comparison between the variance of the temperature and the turbulent kinetic energy. Within the thermal boundary layer, $\left\langle\theta^{\prime 2}\right\rangle$ is seven times higher than $k^{*}$ and harshly fells above for $\left.Y^{*}\right\rangle$ 0.002. However, the turbulent kinetic energy remains almost constant in a wider part that corresponds to the thickness of the dynamic boundary layer. Therefore, it seems that the contribution of the velocity fluctuations to the energy remains almost the same through the dynamic boundary layer, but it is negligible compared to the contribution of the temperature fluctuations within the thermal boundary layer.

\section{Conclusion}

The investigations presented here on turbulent natural convection in the present DHC setup have been carried out thanks to a measurement technique consisting in the simultaneous measurements of velocity by PIV and temperature by micro-thermocouple. It has shown that none of these two methods of measurement are interfering with the other and provide results on the first two statistical moments of the temperature and the velocity of the flow. The mean values velocity and temperature profiles provide an overview of the flow topology at these elevations (boundary layers, recirculation area...). The important magnitude of both the temperature and velocity fluctuations underlines the turbulent 
behavior of this flow. Coupled measurements led to turbulent heat fluxes. Profiles show they are maximum where the buoyancy forces are predominant that is to say in the thermal boundary layer. Turbulent heat fluxes distributions exhibit an evolution of $3^{\text {rd }}$ and $4^{\text {th }}$ order statistical moment (skewness and flatness) depending of the location. Finally, averaged energy equation provides information on the way how heat transfer occurs. It appears that the heat is mainly conveyed by the mean flow in the vertical direction and by the turbulence in the horizontal direction especially in the thermal boundary layer (at the vicinity of the wall). In addition, to enhance the understanding of turbulent natural convection mechanisms, knowledge of the turbulent heat fluxes provides experimental data to compare with DNS calculations [3-4] and this is a way to improve RANS models where these terms have to be modeled.

These coupled and synchronized measurements of both the temperature and the velocity let obtain turbulent heat fluxes and open the access to terms of the Navier-Stokes equations hard to measure such as for instance the motion pressure.

\section{References}

[1] De Vahl Davis, G., "Laminar natural convection in an enclosed rectangular cavity", Int. J. Heat Mass Transf., 11, pp. 1675-1693, (1968).

[2] Henkes, R. A. W. M., Natural Convection Boundary Layers, Ph.D. Thesis, University of Technology of Delft, (1990).

[3] Trias, F. X., Gorobets, A., Soria, M., Oliva, A., "Direct numerical simulation of a differentially heated cavity of aspect ratio 4 with Rayleigh numbers up to $10^{11}$ - Part I: Numerical methods and time-averaged flow", Int. J. Heat Mass Transf., 53, pp. 674-683, (2010).

[4] Trias, F. X., Gorobets, A., Soria, M., Oliva, A., "Direct numerical simulation of a differentially heated cavity of aspect ratio 4 with Rayleigh numbers up to $10^{11}-$ Part II: Heat transfer and flow dynamics”, Int. J. Heat Mass Transf., 53, pp. 665-673, (2010). 
[5] Xin, S., Chergui, J., Le Quéré, P., Dai, R., “Turbulent 3D natural convection flows and interaction with surface radiation in air-filled cavity", Int. Centre Heat Mass Transf., Palermo, 24-27 sept, (2012).

[6] Trias, F. X., Gorobets, A., Pérez-Segarra, C. D., "DNS and regularization modeling of a turbulent differentially heated cavity of aspect ratio 5", Int. J. Heat Mass Transf., 57, pp. 171182, (2013).

[7] Sergent, A., Xin, S., Joubert, P., Le Quéré, P., Salat, J., Penot, F., "Resolving the stratification discrepancy of turbulent natural convection in differentially heated air-filled cavities. Part I: Reference solutions using Chebyshev spectral methods", Int. J. Heat Fluid Flow, 39, pp. 1-14, (2013).

[8] Sergent, A., Joubert, P., Xin, S., Le Quéré, "Resolving the stratification discrepancy of turbulent natural convection in differentially heated air-filled cavities. Part II: End walls effects using large eddy simulation", Int. J. Heat Fluid Flow, 39, pp. 15-27, (2013).

[9] Xin, S., Salat, J., Joubert, P., Sergent, A., Penot, F., Le Quéré, "Resolving the stratification discrepancy of turbulent natural convection in differentially heated air-filled cavities. Part III: A full convection-conduction-surface radiation coupling”, Int. J. Heat Fluid Flow, 42, pp. 3348, (2013).

[10] De Larochelambert, T., "Transition to turbulence in strongly heated vertical natural convection boundary layers", Proc of Eurotherm Sem., 74, pp 183-188 (2003).

[11] Saury, S., Rouger, N., Djanna, F., Penot, F., "Natural convection in an air-filled cavity: experimental results at large Rayleigh numbers", Int. Com. in Heat and Mass Tr., 38, pp.679687, (2011).

[12] Thole, K. A., Bogard, D. G., "Simultaneous temperature and velocity measurements", Meas. Sci. Technol., 5, pp. 435-439, (1994). 
[13] Pietri, L., Amielh, M., Anselmet, F., "Simultaneous measurements of temperature and velocity fluctuations in a slightly heated jet combining a cold wire and laser Doppler anemometry", Int. J. of Heat and Fluid Flow, 21, pp. 22-36, (2000).

[14] Wardana, I. N. G., Ueda, T., Mizomoto, M., "Velocity-temperature correlation in strongly heated channel flow", Experimental in Fluids, 18, pp. 454-462, (1995).

[15] Felis, F., Pavageau, M., Elicer-Cortés, J. C., Dassonville, T., "Simultaneous measurements of temperature and velocity fluctuations in a double stream-twin jet air curtain for heat confinement in case of tunnel fire", Int. J. of Heat and Fluid Flow, 21, pp. 22-36, (2000).

[16] Germain F., Applying Plannar Laser Induced Fluorescence to a Mixed Convection Air Flow: Characterisation and Simulation, Ph.D. Thesis, University of Poitiers, (2015).

[17] Jašíková D., Švarc P., Dvoák V., Kopecký V., "Fluid velocity and LIF temperature measurement in a real model of heat exchanger", EPJ Web of Conf., 25, 02009 (2012).

[18] Ilie, A., Saury, D., Lemonnier, D., Belleoud, P., "Coupled temperature and velocity measurements in turbulent natural convection flows", J. Phys.: Conf. Ser., 395, 012067, (2012).

[19] Belleoud P., Etude de la convection naturelle turbulente en cavité verticale différentiellement chauffée : analyse des structures et des transferts turbulents, Ph.D. Thesis, University of Poitiers, (2016).

[20] Belleoud P., Saury D., Joubert P., Lemonnier D., Djanna F., "Experimental investigations in an air-filled differentially-heated cavity at large Rayleigh Numbers", J. Phys.: Conf. Ser., 395, 012119, (2012).

[21] Salat J., Xin S., Joubert P., Sergent A., Penot F., Le Quéré P., "Experimental and numerical investigation of turbulent natural convection in a large air-filled cavity", Int. J. of Heat and Fluid Flow, 25, pp. 824-832, (2004). 
[22] Soria M., Trias F. X., Pérez-Segarra C. D., Oliva A., "Direct numerical simulation of a threedimensional naturalconvection flow in a differentially heated cavity of aspect ratio 4", Num. Heat Transf., Part A, 45, pp 649-673, (2004).

[23] Elghobashi S. E., Launder B. E., "turbulent time scales and the dissipation rate of temperature variance in the thermal mixing layer", Phys. of Fluids, 26, 2415, (1983).

[24] Otic I., Grötzbach G.,"Analysis of turbulent diffusion in the temperature variance dissipation rate equation”, Proc. Appl. Math. Mech., 4, pp. 490-491, (2004).

[25] Matt S., Hou W, Goode W, Josset D, “Turbulent kinetic energy and temperature variance dissipation in laboratory generated Rayleigh-Bénard turbulence designed to study the distortion of light by underwater microstructure fluctuations", Current, Waves and Turbulence Measurement (CWTM), 2015 IEEE/OES Eleventh, 15110318, (2015). 

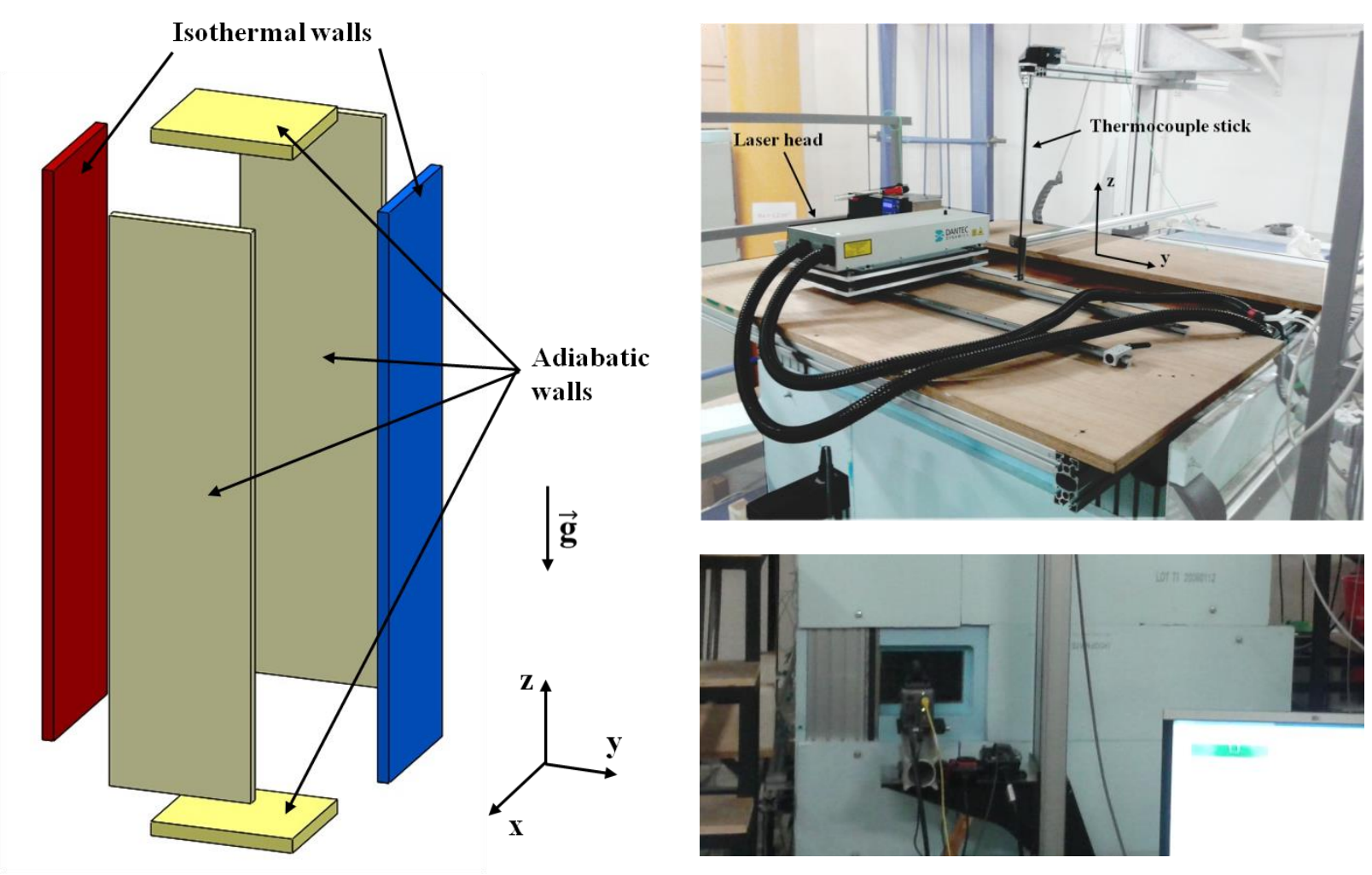

Figure 1: Schematic view of the cavity (left) and pictures of the roof of the cavity with both the laser head and the thermocouple stick (top right) and of the front side of the cavity (bottom right). 


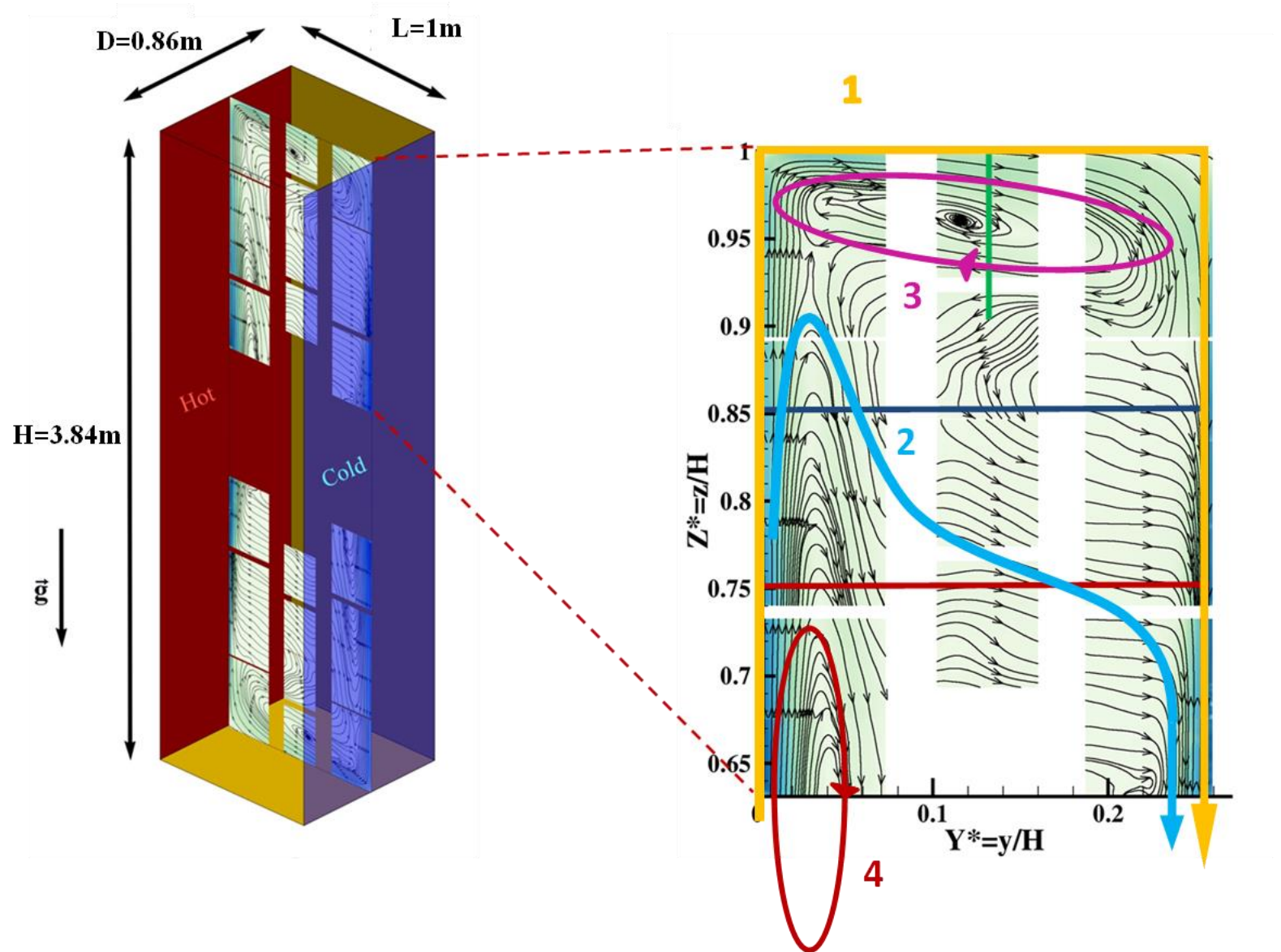

Figure 2: General flow circulations in the vertical mid-depth plane obtained with the acquisition of 18 PIV fields $\left(18 \times 28 \mathrm{~cm}^{2}\right.$ each) averaged over 1120 image pairs at $4 \mathrm{~Hz}\left(\right.$ i.e. $4 \mathrm{~min} 40 \mathrm{~s}$ per acquisition) for $R a_{H}=1.2 \times 10^{11}$. 

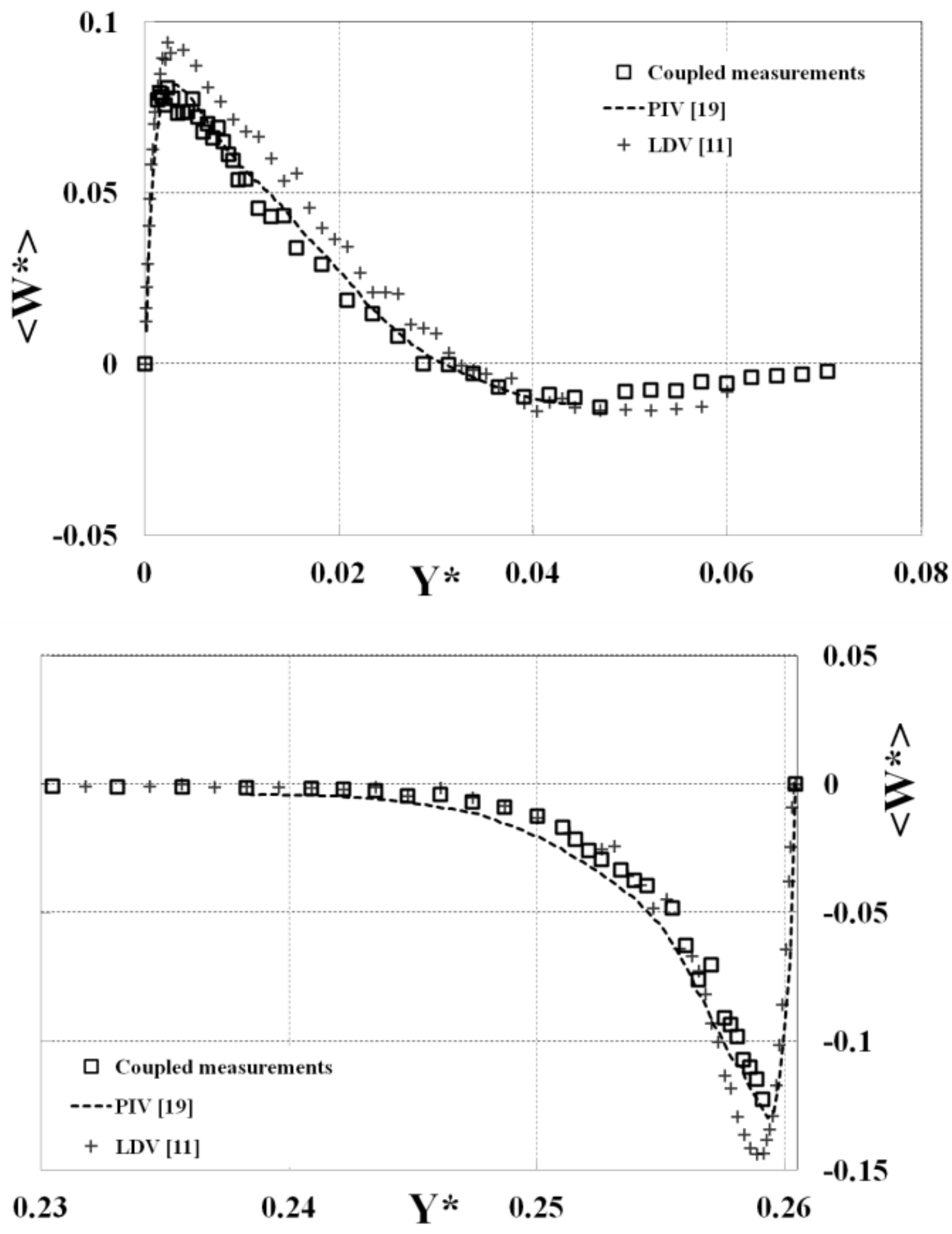

Figure 3: Vertical component of the velocity acquired by LDV [11], PIV [19] and coupled measurements of velocity and temperature at $Z^{*}=0.85$ for $R a_{H}=1.2 \times 10^{11}$. 

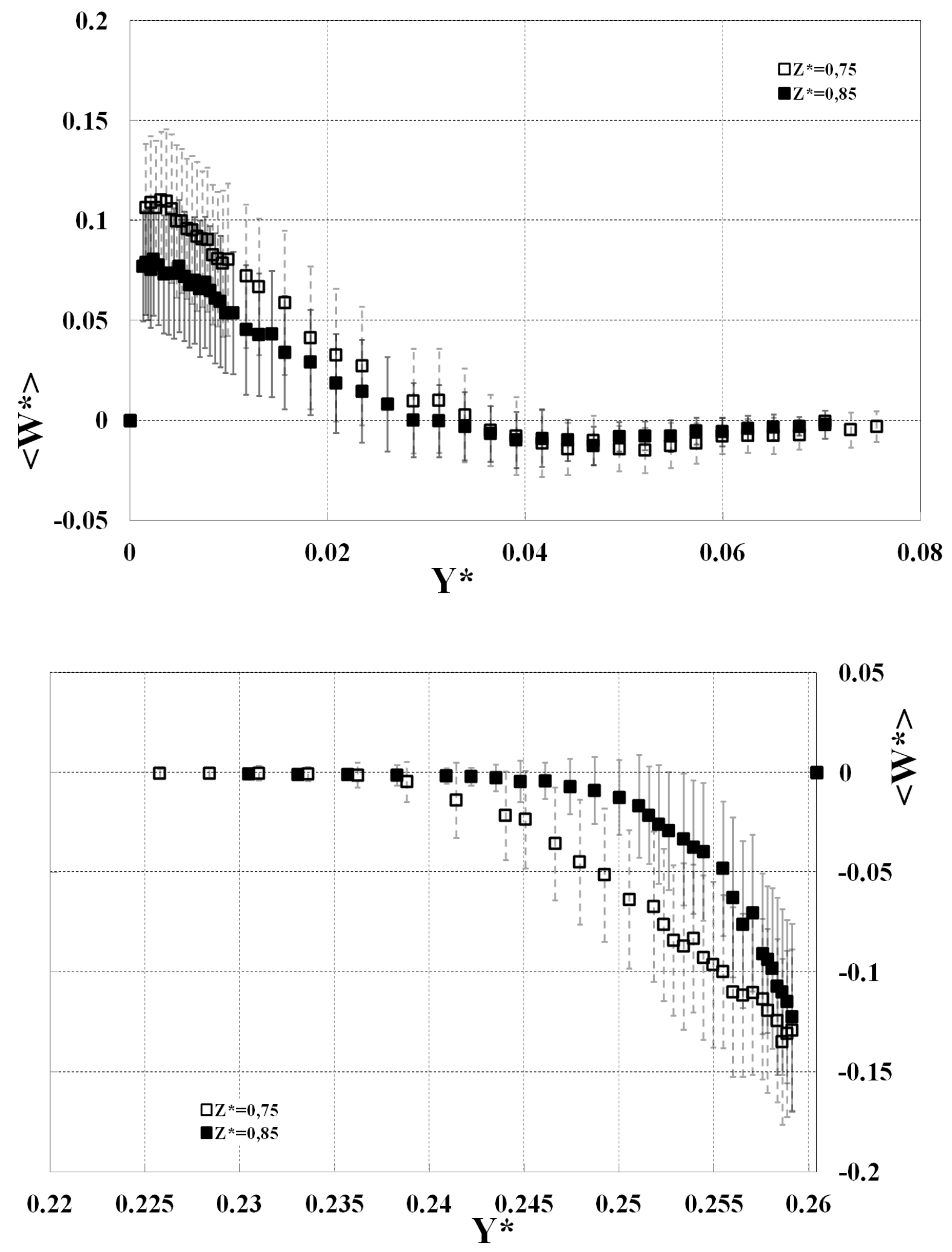

Figure 4: Mean dimensionless vertical component of the velocity at $Z^{*}=0.75$ and $Z^{*}=0.85$ near the hot wall (top) and near the cold wall (bottom) with RMS values (bar) for $R a_{H}=1.2 \times 10^{11}$. 

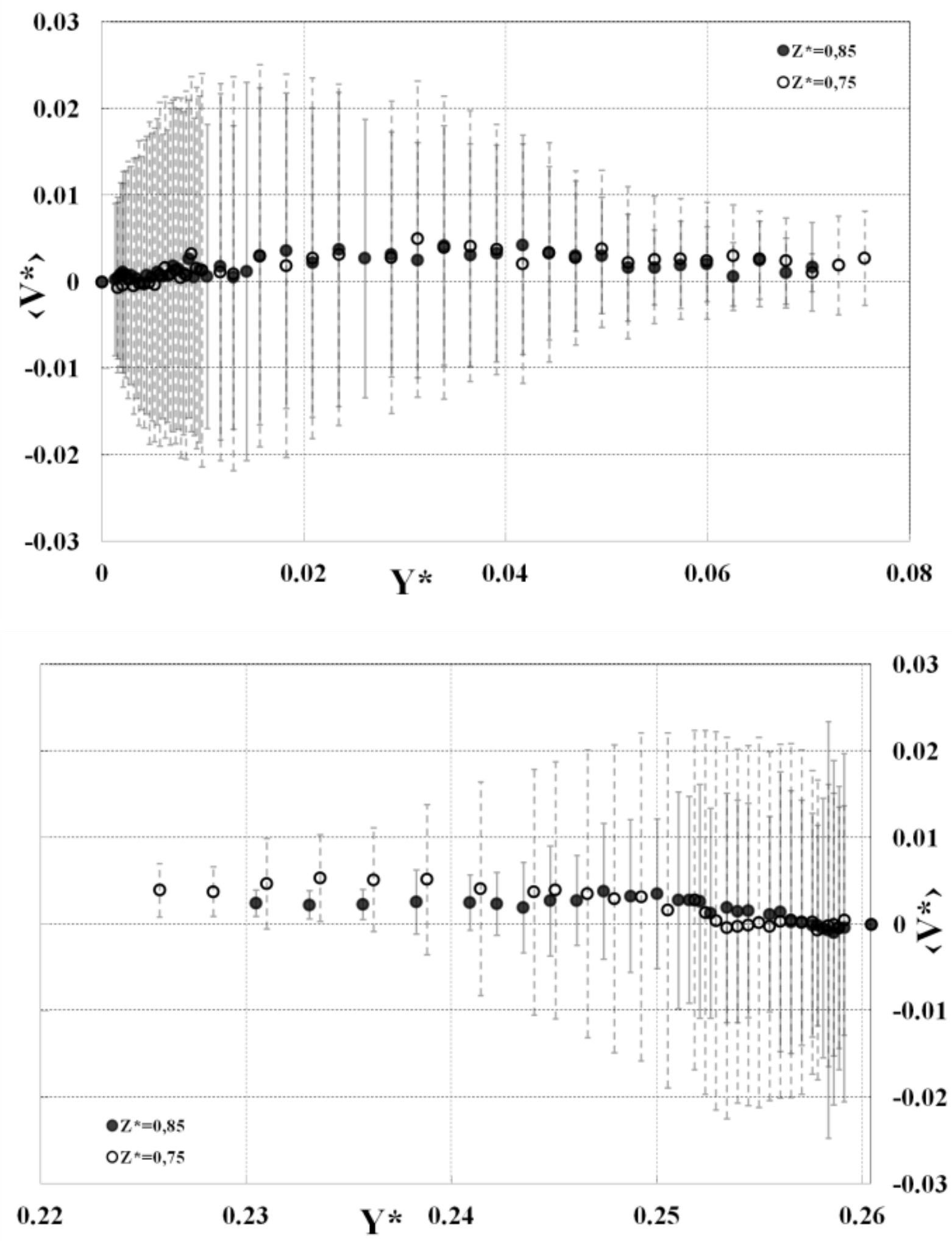

Figure 5: Mean dimensionless horizontal component of the velocity at $Z^{*}=0.75$ and $Z^{*}=0.85$ near the hot wall (top) and near the cold wall (bottom) with RMS values (bar) for $R a_{H}=1.2 \times 10^{11}$. 
P. Belleoud, D. Saury, D. Lemonnier, "Coupled velocity and temperature measurements in an air-filled differentially heated cavity at large Rayleigh Numbers $(\mathrm{Ra}=1.2 \times 1011)$ ", International Journal of Thermal Sciences, Volume 123, pp. 151-161, 2018. doi:10.1016/j.ijthermalsci.2017.09.018
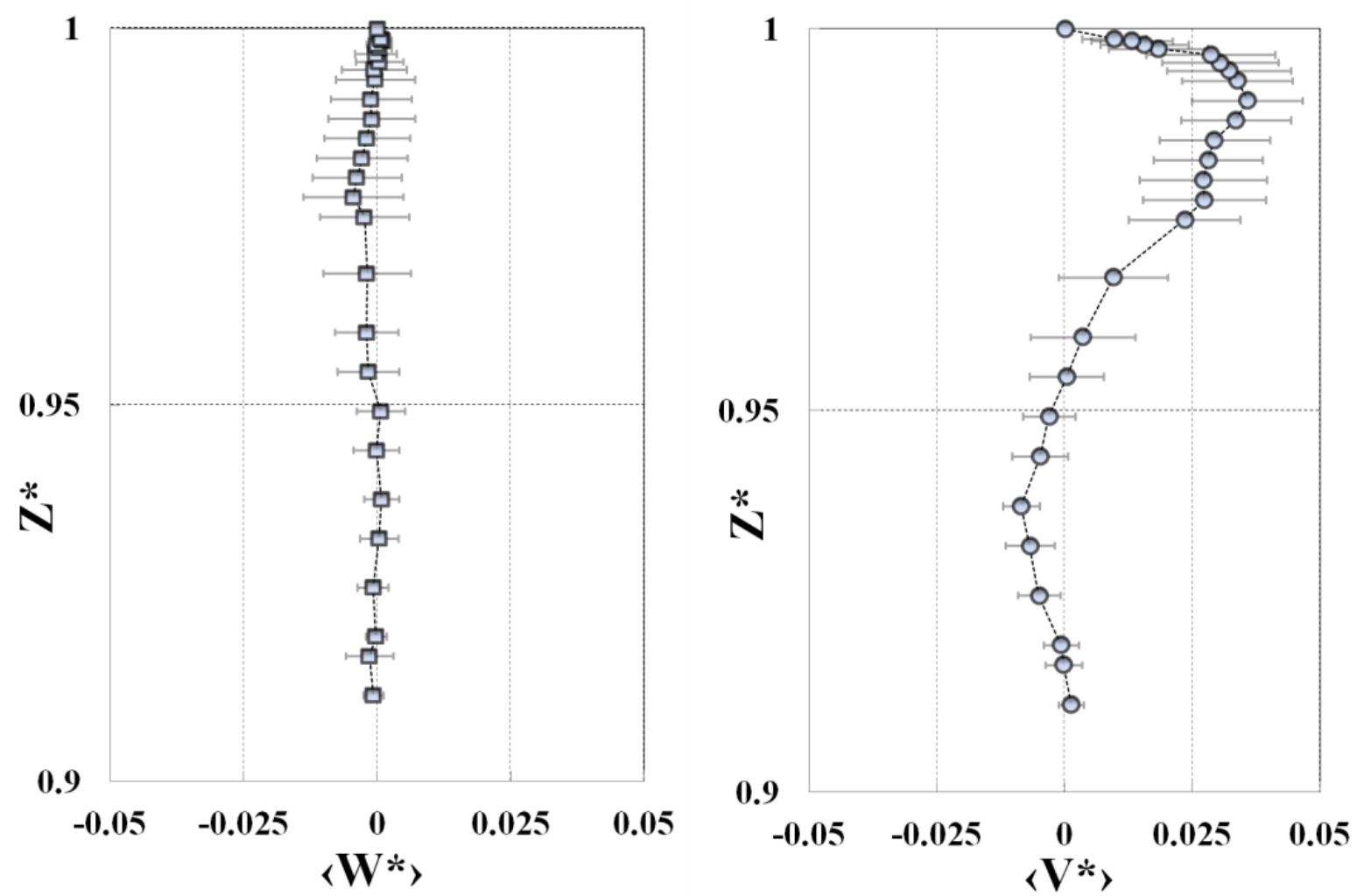

Figure 6: Mean dimensionless vertical (left) and horizontal (right) components of the velocity with RMS values (bar) near the roof the cavity at mid width for $R a_{H}=1.2 \times 10^{11}$. 

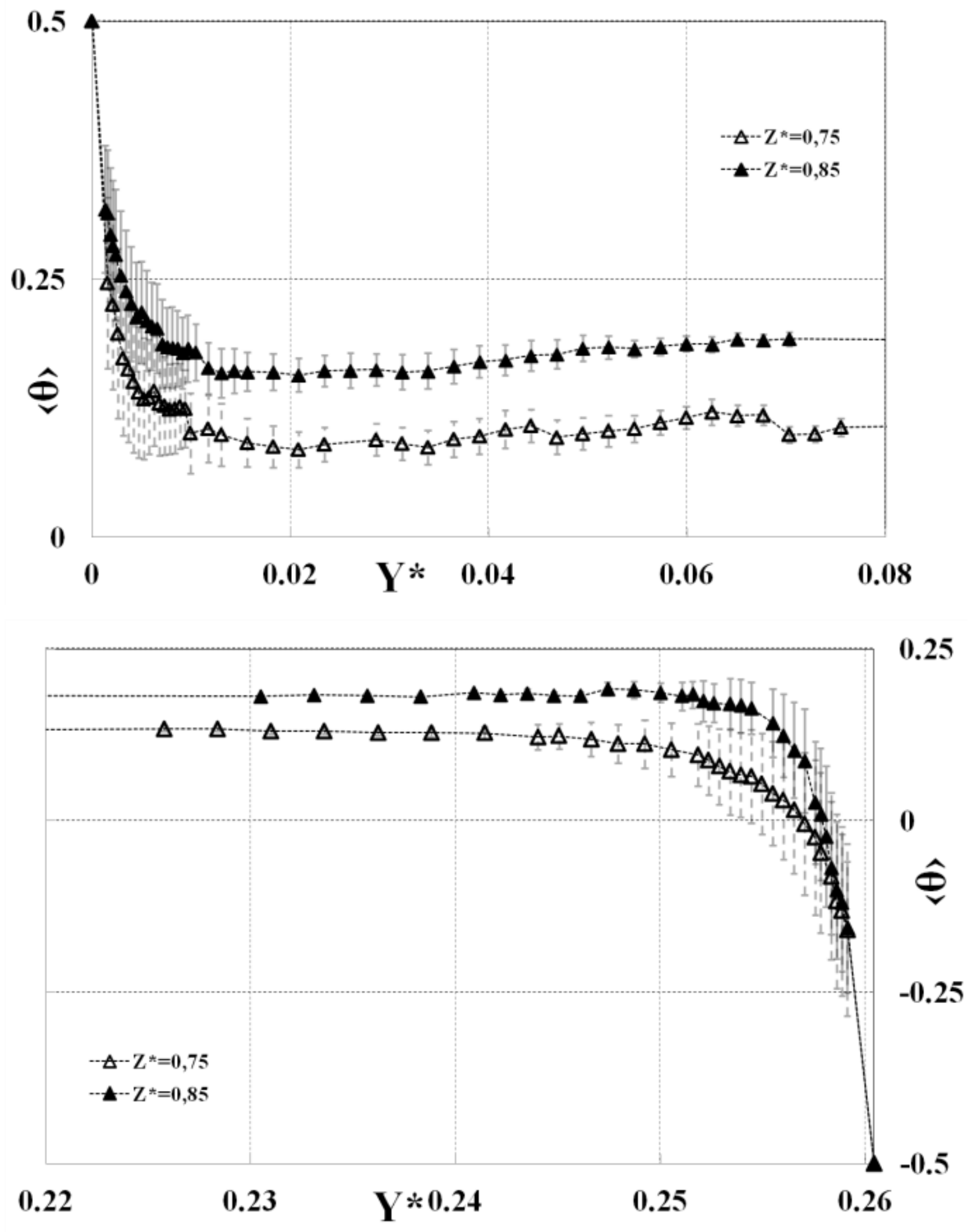

Figure 7: Mean dimensionless temperature at $Z^{*}=0.75$ and $Z^{*}=0.85$ near the hot wall (top) and near the cold wall (bottom) with RMS values (bar) for $R a_{H}=1.2 \times 10^{11}$. 
P. Belleoud, D. Saury, D. Lemonnier, "Coupled velocity and temperature measurements in an air-filled differentially heated cavity at large Rayleigh Numbers $(\mathrm{Ra}=1.2 \times 1011)$ ", International Journal of Thermal Sciences, Volume 123, pp. 151-161, 2018. doi:10.1016/j.ijthermalsci.2017.09.018

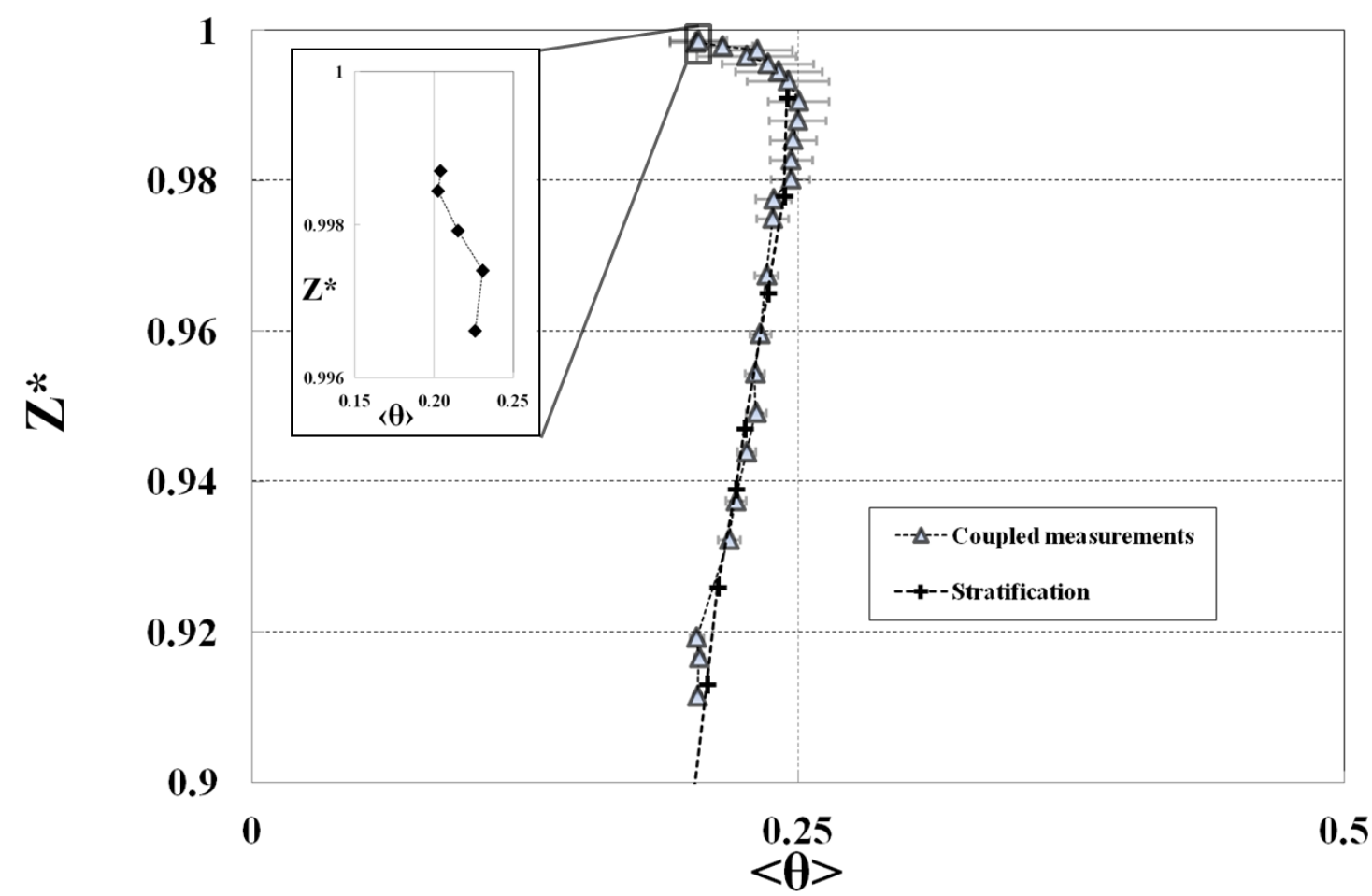

Figure 8: Mean dimensionless temperature with RMS values (bar) near the roof the cavity at mid width for $R a_{H}=1.2 \times 10^{11}$. 


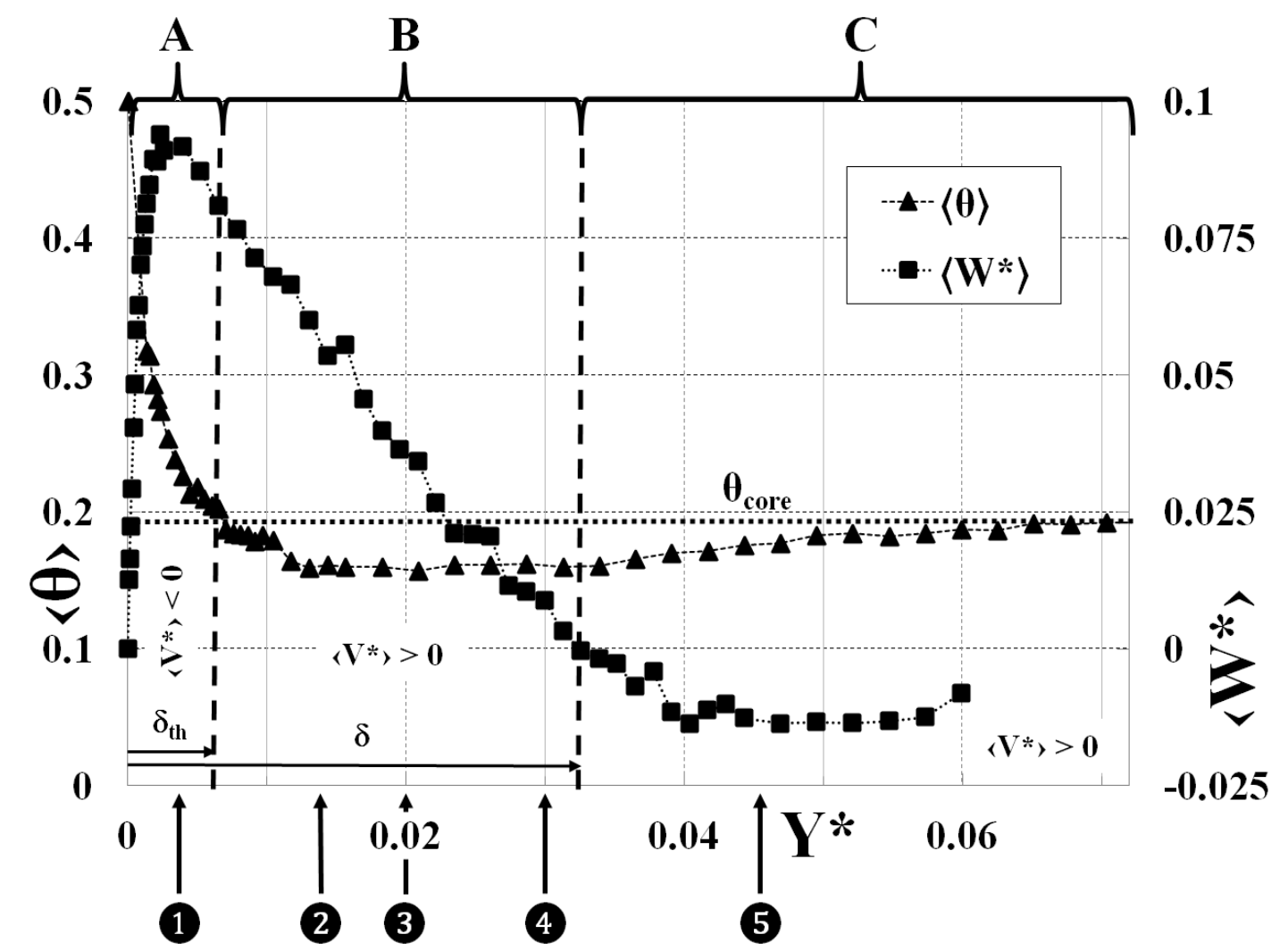

Figure 9: Dimensionless temperature and vertical velocity profiles near the hot wall at $Z^{*}=0.85$ for $R a_{H}=1.2 \times$ $10^{11}$. 


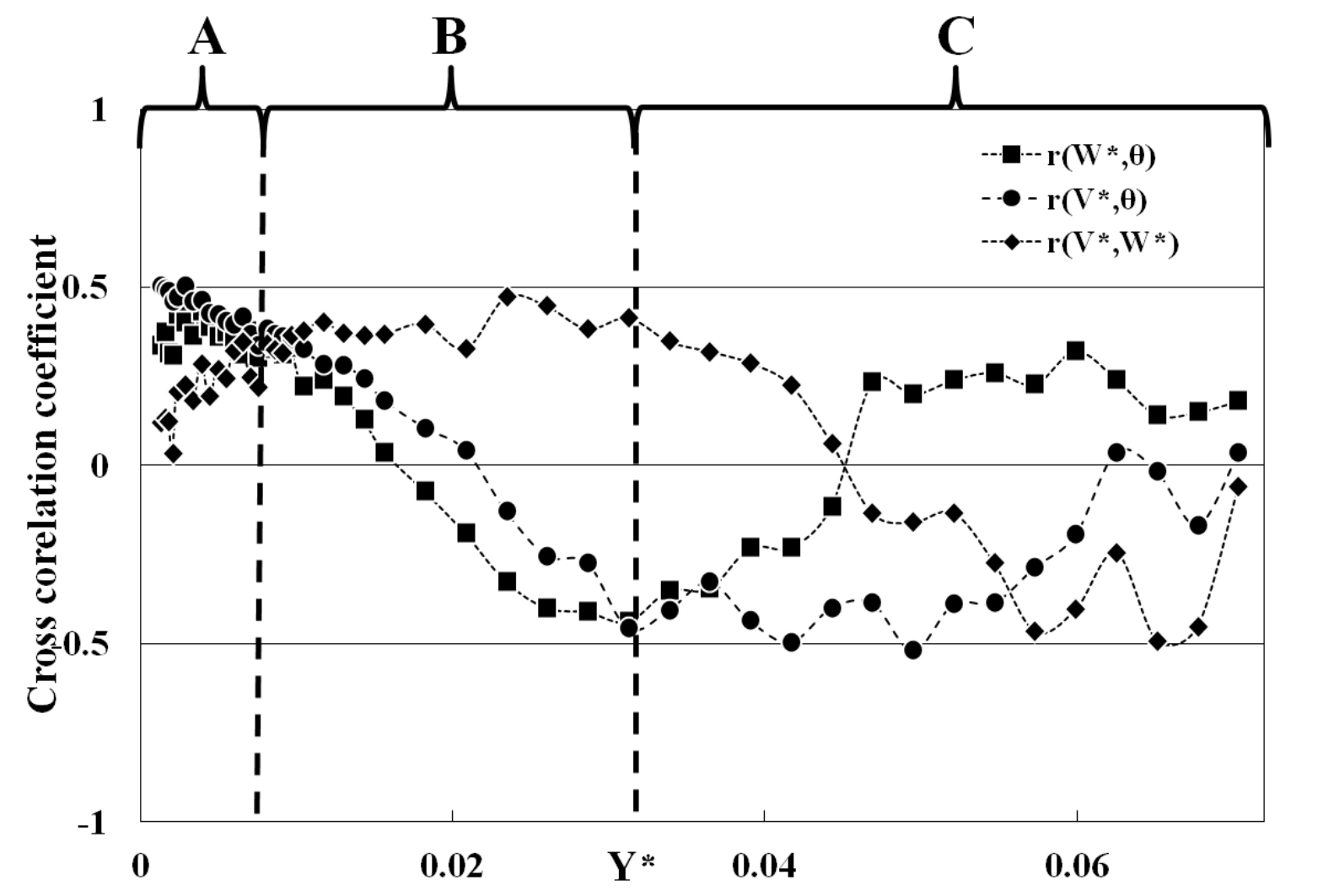

Figure 10: Cross correlation coefficients between $W^{*}, V^{*}$ and $\theta$ at $Z *=0.85$ near the hot wall for $R a_{H}=1.2 \times 10^{11}$. 
P. Belleoud, D. Saury, D. Lemonnier, "Coupled velocity and temperature measurements in an air-filled differentially heated cavity at large Rayleigh Numbers $(\mathrm{Ra}=1.2 \times 1011)$ ", International Journal of Thermal Sciences, Volume 123, pp. 151-161, 2018. doi:10.1016/j.ijthermalsci.2017.09.018
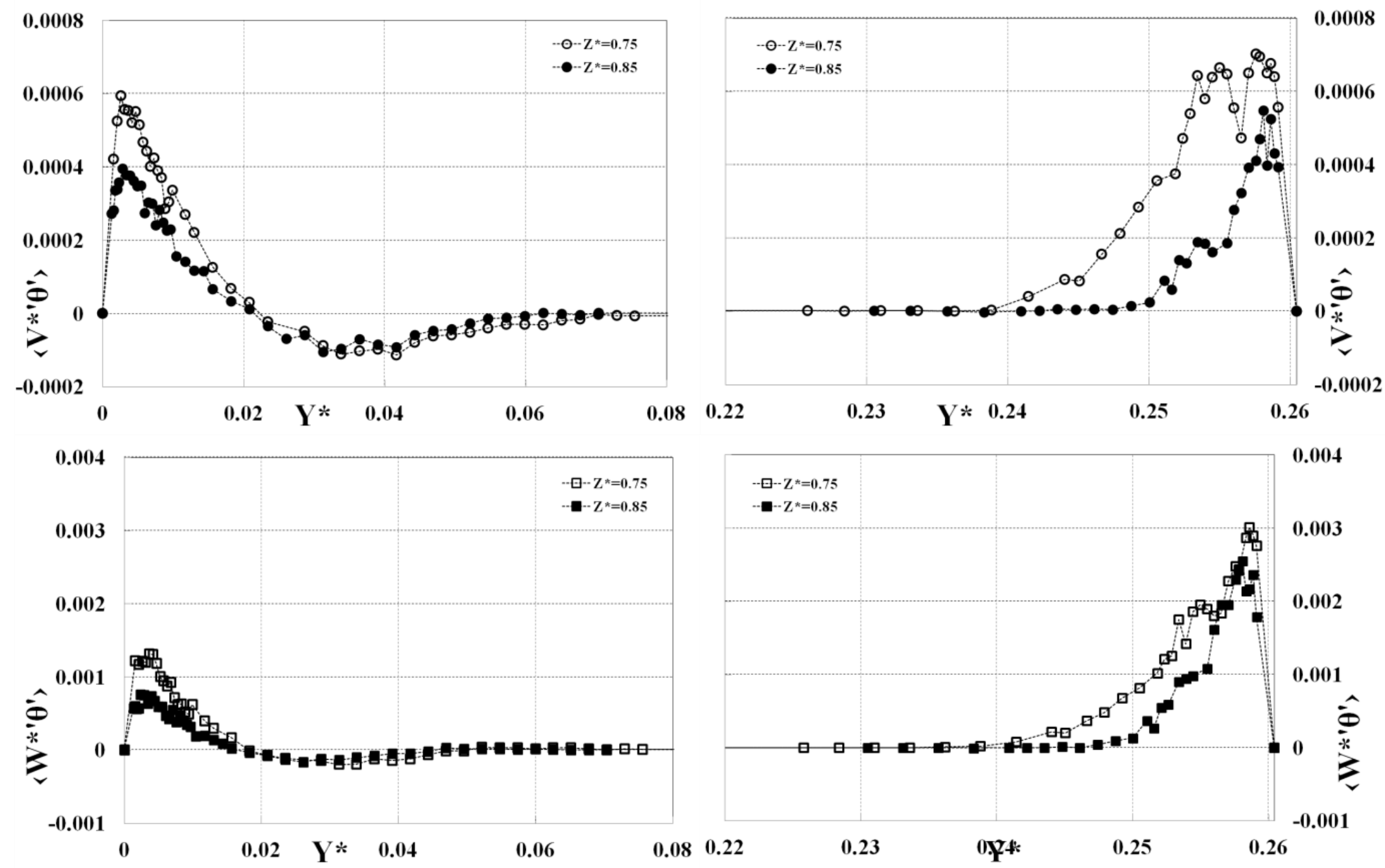

Figure 11: Horizontal (top) and vertical (bottom) dimensionless turbulent heat fluxes at $Z^{*}=0.75$ and $Z^{*}=0.85$ for $R a_{H}=1.2 \times 10^{11}$. 

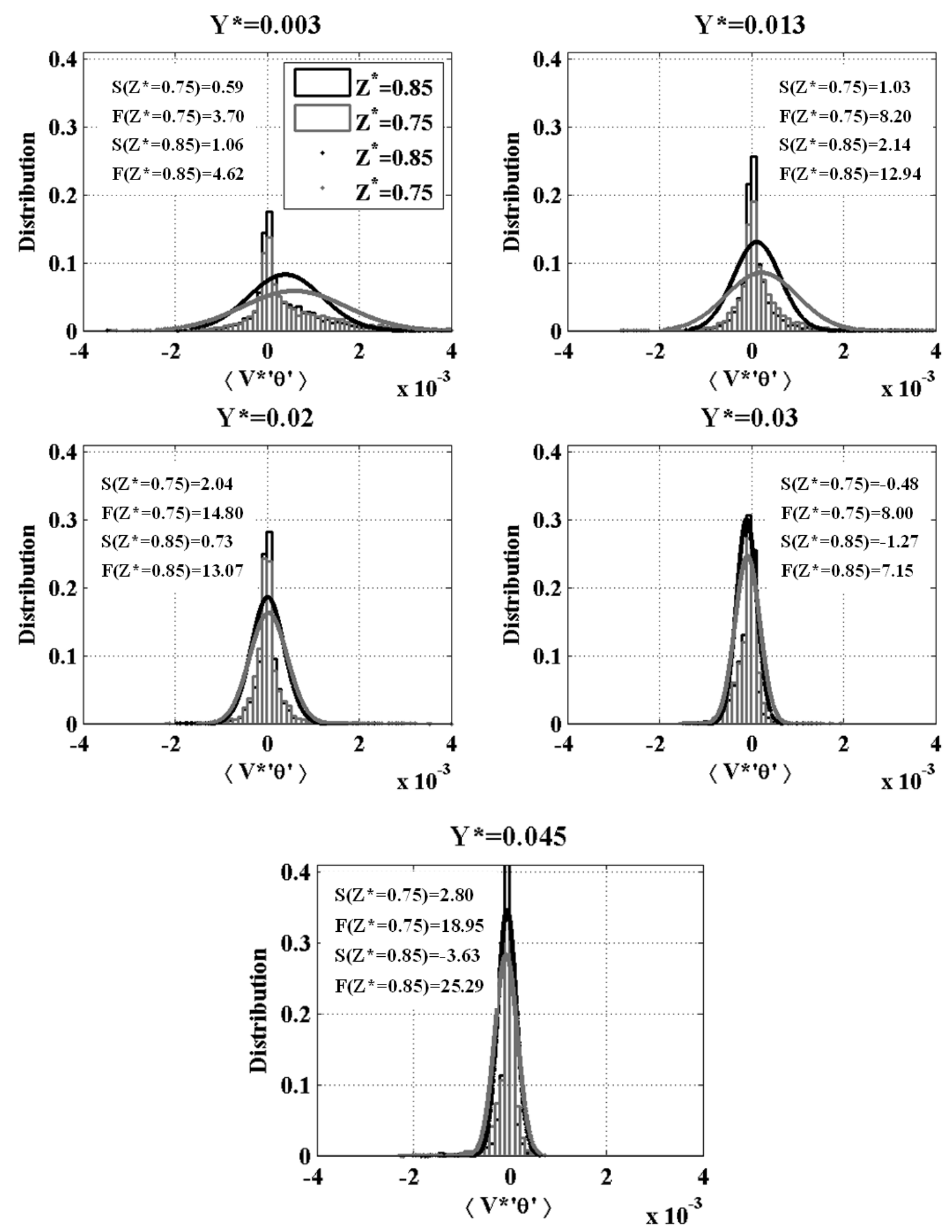

Figure 12: Distribution of the horizontal dimensionless turbulent heat flux and the related normal distribution for different $Y^{*}$ with the values of the skewness $(S)$ and the flatness $(F)$ at $Z^{*}=0.75$ (gray) and $Z^{*}=0.85$ (black) for $R a_{H}=1.2 \times 10^{11}$. 

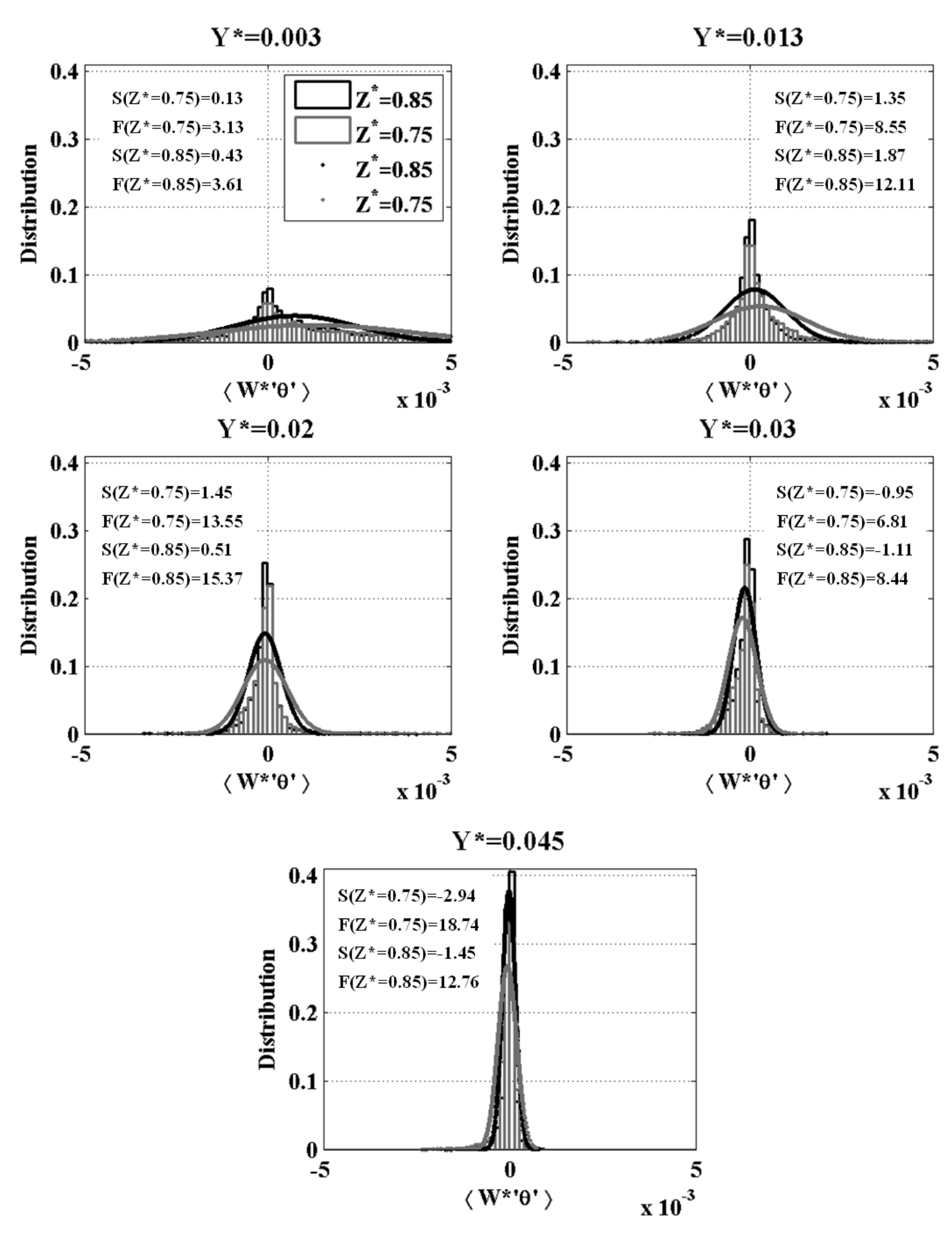

Figure 13: Distribution of the vertical dimensionless turbulent heat flux and the related normal distribution for different $\mathrm{Y}^{*}$ with the values of the skewness $(\mathrm{S})$ and the flatness $(\mathrm{F})$ at $\mathrm{Z}^{*}=0.75$ (gray) and $\mathrm{Z}^{*}=0.85$ (black) for $R a_{H}=1.2 \times 10^{11}$. 
P. Belleoud, D. Saury, D. Lemonnier, "Coupled velocity and temperature measurements in an air-filled differentially heated cavity at large Rayleigh Numbers $(\mathrm{Ra}=1.2 \times 1011)$ ", International Journal of Thermal Sciences, Volume 123, pp. 151-161, 2018. doi:10.1016/j.ijthermalsci.2017.09.018
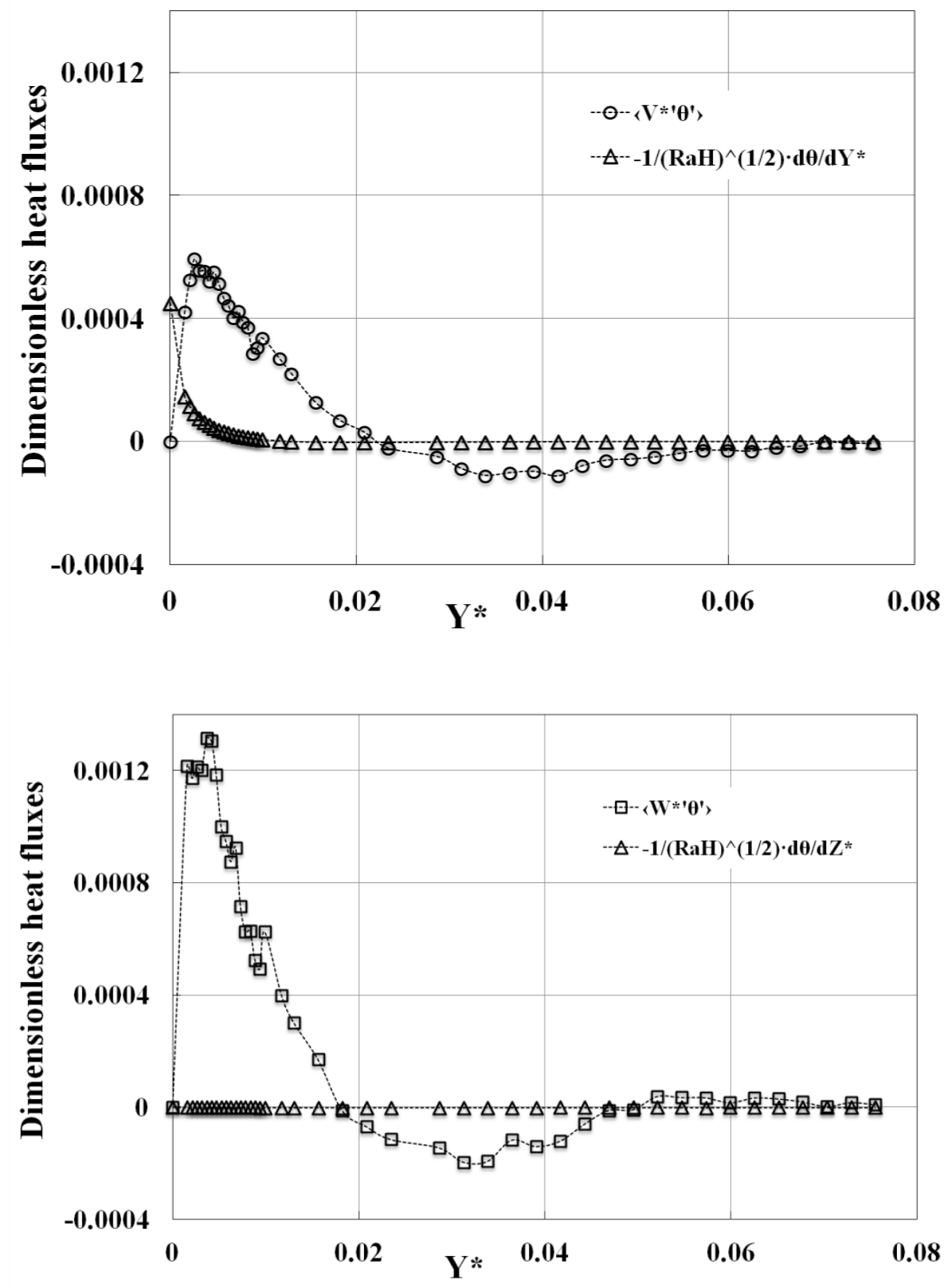

Figure 14: Dimensionless heat fluxes due to the fluctuations (circles and squares) and to the conduction (triangles) at $Z^{*}=0.75$ for $R a_{H}=1.2 \times 10^{11}$. 
P. Belleoud, D. Saury, D. Lemonnier, "Coupled velocity and temperature measurements in an air-filled differentially heated cavity at large Rayleigh Numbers $(\mathrm{Ra}=1.2 \times 1011)$ ", International Journal of Thermal Sciences, Volume 123, pp. 151-161, 2018. doi:10.1016/j.ijthermalsci.2017.09.018
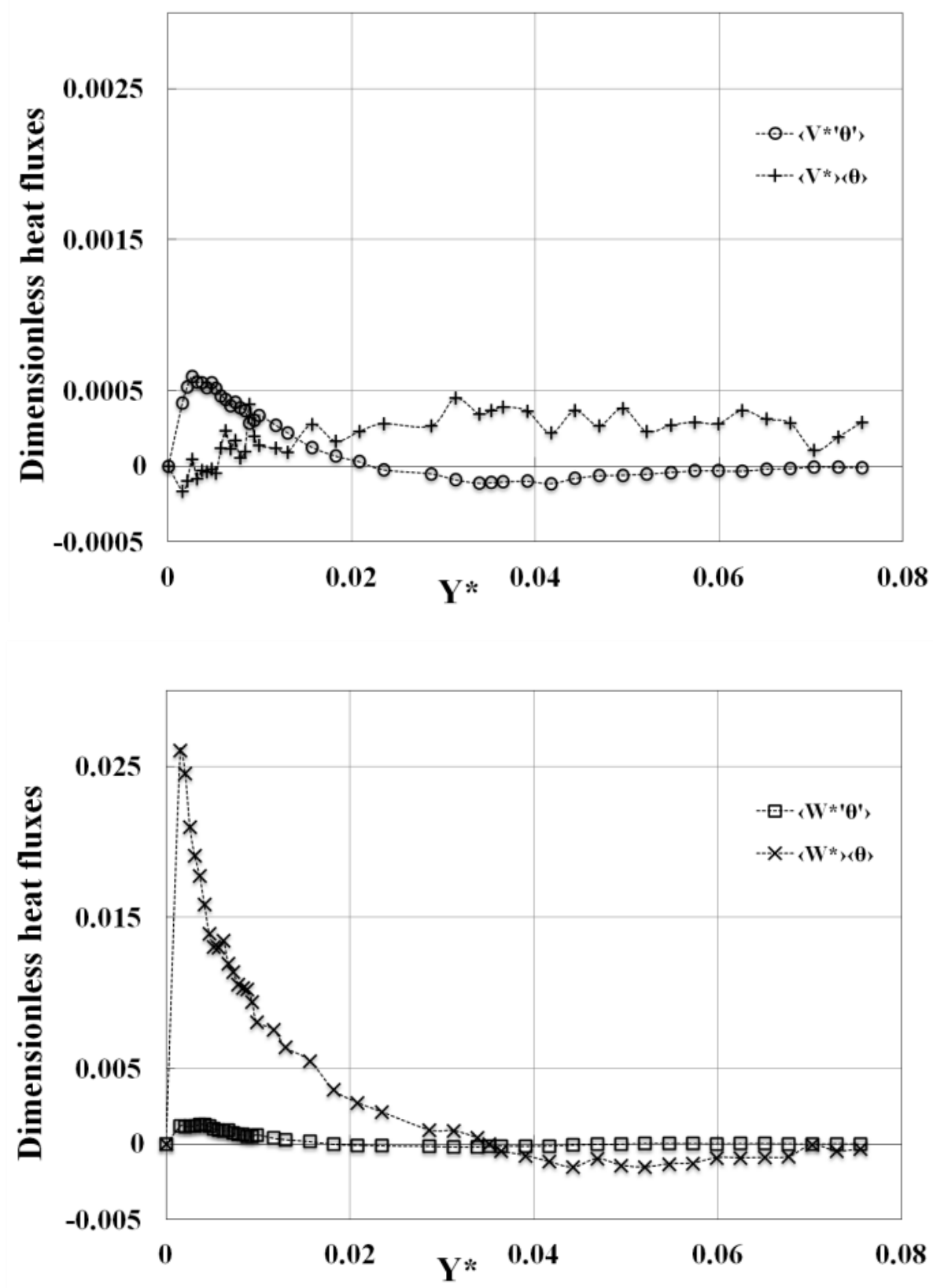

Figure 15: Dimensionless heat fluxes due to the fluctuations and to the mean flow at $Z^{*}=0.75$ for $R a_{H}=1.2 \times 10^{11}$. 

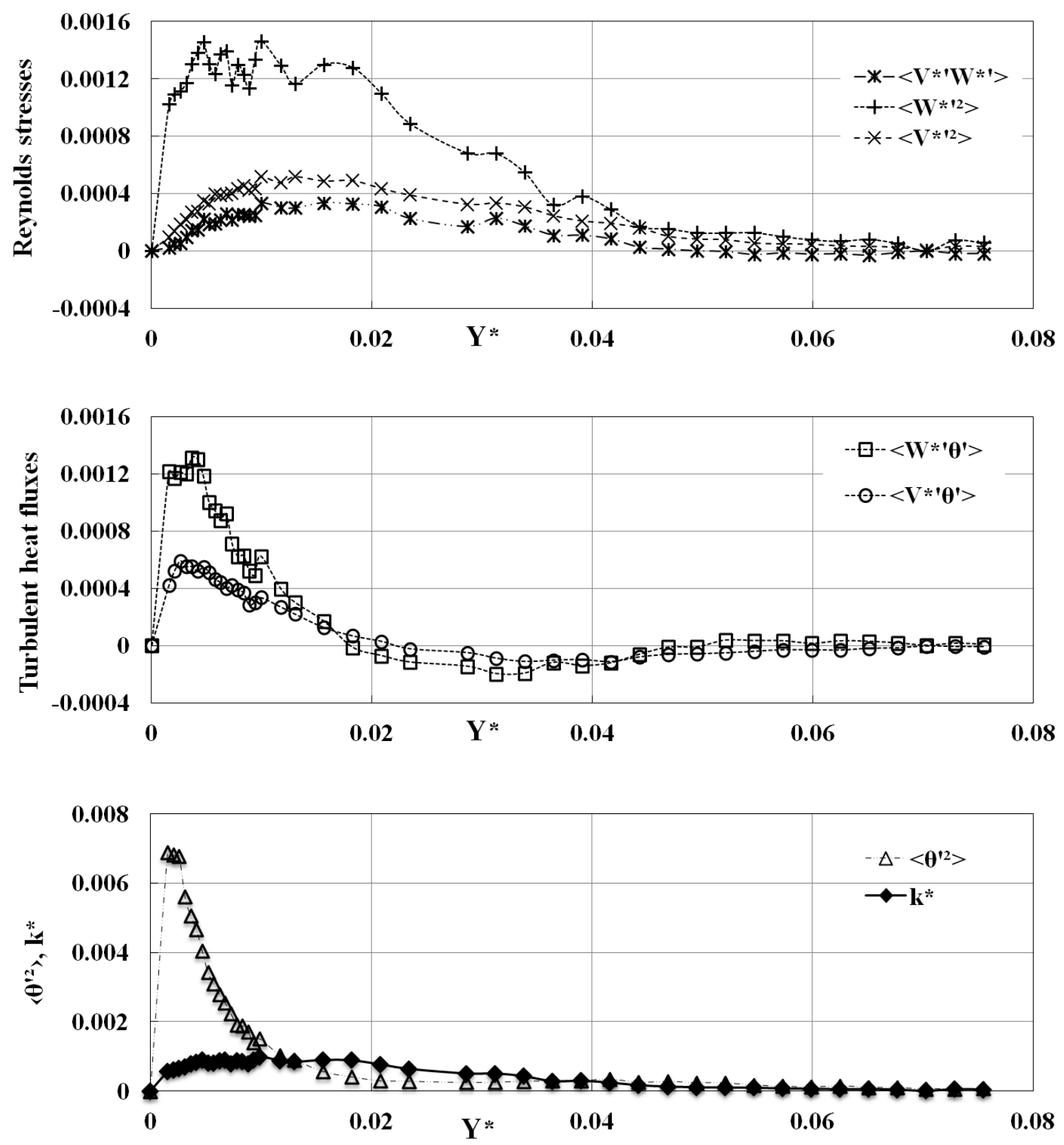

Figure 16: Turbulent heat fluxes, Reynolds stresses, variance of the temperature and turbulent kinetic energy near the hot wall at $Z^{*}=0.75$ for $R a_{H}=1.2 \times 10^{11}$. 